\section{The Power of a}

\section{Mindful Moment}

\section{Betsy Diamant-Cohen and Katie Scherrer}

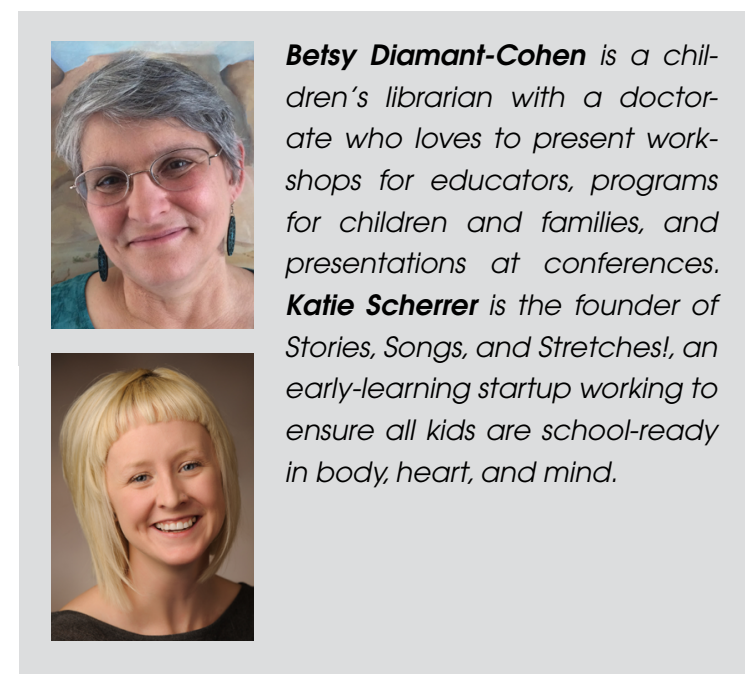

$\mathrm{M}$ indfulness, a practice of intentionally connecting with the present moment as it is, is finally taking root in libraries. Practiced for millennia, mindfulness has long been recognized by the business community as a critical leadership skill. Academic libraries have taken the lead in melding mindfulness and librarianship, as evidenced by the boom in designated academic library space for quiet mindfulness practice and the 2015 publication of The Mindful Librarian: Connecting the Practice of Mindfulness to Librarianship. ${ }^{1}$

Mindfulness is a muscle we build through consistent practice, much like we build physical muscles by regularly lifting weights. As we build the muscle of mindfulness, we may notice more calm and optimism in our lives because we are relating to the world differently, with less reactivity. What an incredible skill for children to develop at a young age!

Public librarians serving youth are beginning to experiment with simple strategies for incorporating mindfulness into their work with children and families, and an abundance of titles for children on this topic have emerged in the last several years. The resources highlighted in this article are presented to help curious librarians learn more about mindfulness, develop their personal mindfulness practice, understand how mindfulness can benefit the families they serve, and begin experimenting with embedding mindful moments into their work with children.

\section{Mindfulness and Trauma}

Perhaps one of the most powerful benefits of mindfulness is the positive way it can impact-at both neurophysiological and behavioral levels-those who have been affected by trauma, including children experiencing adverse childhood experiences (ACEs), long known to be indicators of physical, mental, and relational difficulties in adulthood. The Complex Post-Traumatic Stress Disorder Foundation provides an easy-to-understand explanation of the relationship between ACEs, neuroplasticity, and mindfulness in the article "Trauma-Informed Care, Neuroplasticity and Mindfulness." ${ }^{2}$

Two recent scientific articles that explore mindfulness, trauma, and early childhood more thoroughly are available from the National Institutes of Health. An extensive literature review published in Children in 2017 found that "high-quality, structured mindfulness instruction may mitigate the negative effects of stress and trauma related to adverse childhood exposures, improving short- and long-term outcomes, and potentially reducing poor health outcomes in adulthood." ${ }^{3}$ Another 2017 article (published in Child and Adolescent Psychiatric Clinics in North America) finds that mindfulness-based practices hold great promise for helping traumaaffected children and families build protective resilience and improve parental stress management and engagement, yet these practices are dramatically underused. ${ }^{4}$ 


\section{Insight Timer}

https://insighttimer.com

This free app, available for iOS and Android devices, provides access to more than sixty thousand guided meditations from a variety of traditions, including Mindfulness Based Stress Reduction (MBSR). Meditations can be filtered by topic, teacher, or time. Meditations specifically created for children are available. A timer with multiple chime sounds to choose from is also free with the app.

\section{Mindfulness for Librarians Facebook Group}

www.facebook.com/groups/mindfulnessforlibrarians

Administrated by several of the editors of The Mindful Librarian, this closed Facebook group is an excellent place to connect with other professionals integrating mindfulness into library work. Its active membership shares practice opportunities, articles, book reviews, and general support and has even begun experimenting with virtual practice sessions.

\section{Collaborative Association for Social and Emotional Learning (CASEL)}

https://casel.org

CASEL is leading the way nationally to strenghten socialemotional learning (SEL) throughout the lifespan. They provide extensive research and developmental best practices, evaluate curriculums and programs, and inform policy decisions. A must-know organization for anyone who cares about whole-child development.
The Calm Schools Initiative

www.calm.com/schools

Aimed at building mindfulness in schools, this initiative provides training and resources free of charge to K-12 teachers worldwide. A subscription version is also available to those not working in the school setting, and some free resources are universally available.

\section{Taking Care}

https://sesamestreetincommunities.org/topics/traumatic -experiences/?activity=taking-care

This site uses familiar characters to promote mindfulness techniques. Examples of freely available resources include "I Can Calm Myself Down” (a video featuring Cookie Monster), "Slow Down and Settle Down" (a video with techniques for helping children deal with anxiety), "Helping Kids Calm and Soothe Themselves" (an article), and "Creating Feelings of Safety and Calm” (printable yoga instructions featuring Grover).

Parental Mindfulness and Preschool Children's Emotion Regulation: The Role of Mindful Parenting and Secure ParentChild Attachment

https://link.springer.com/article/10.1007/s12671-019-01120-y We know that a strong bond between children and their parents in the earliest years is an important factor in healthy development. That is why libraries run family engagement programs and give development tips to parents. Although research into mindfulness is a relatively new field, this article describes a study involving 472 parents of preschoolers from ages three to six in China that examined the influence that parent mindfulness had their children's emotional regulation and how parent mindfulness affected the entire family, strengthening parent-child bonding. \&

and Trauma," Children (March 2017), www.ncbi.nlm.nih. gov/pmc/articles/PMC5368427.

4. Christina Bethell et al., "Adverse Childhood Experiences, Resilience and Mindfulness-Based Approaches: Common Denominator Issues for Children with Emotional, Mental, or Behavioral Problems," Child and Adolescent Psychiatric Clinics of North America 25, no. 2 (April 2016), www.ncbi.nlm.nih.gov/pmc/articles/PMC4863233. 